\title{
Eski Uygurca Buddhāvatainsaka-sūtra Tefsirine İlişkin Belgeler (20, 27, 28 ve 29. Yapraklar)
}

\author{
Uğur UZUNKAYA* \\ Tümer KARAAYAK**
}

\begin{abstract}
Öz
Sanskritçe Buddhāvataìsaka-sūtra 'çiçek bezeme sūtrası' ve Çince tercümesiyle Huayan jing Budizmin en hacimli eserlerinden biridir. Buddhāvatamssaka-sūtra Budizmin Çin'de oluşum gösteren ve daha sonra Doğu Asya'ya yayıllan Huayan ekolünün de yazınsal temelini oluşturur. Bu ekol dünyadaki bütün olguların birbiriyle karşılıklı iç içe geçmiş olduğu düşüncesini temel alır. Bu çalışma daha önce yayımlanmamış Eski Uygurca Buddhāvatamsaka-sūtra tefsirine ait metin parçaları hakkındadır. Bugün bu fragmanlar Berlin Brandenburg Bilimler Akademisi Turfan Koleksiyonu'nda sirasıly U 1320 ([T I L] 3), U 1309 ([T I] 7), U 1307 ([T I] 8) ve U 1305 ([T I] 9) envanter numaralarıla korunmaktadır. Mevzubahis bu fragmanlar Budizmin Yogācāra ekolünden gelişen Faxiang ekolüne ilişkin metin/metin parçalarının yer aldığı en az otuz bölümden oluşan bir derleme eser niteliğindeki Eski Uygurca yazma eserin 20. bölümünün 20, 27, 28 ve 29. yapraklarını oluşturmaktadır. Bu çalışmada bahsi geçen fragmanların çeviri yazıları ve harf çevirileri, Türkiye Türkçesine aktarmaları, metne ilişkin açıklamaları ve analitik dizini de ihtiva eden sözlüğü sunulacaktır.
\end{abstract}

Anahtar Kelimeler: Budizm, Buddhāvataìsaka-sūtra, Huayan ekolü, Eski Uygurca, metin neşri.

\footnotetext{
* Dr. Erzurum Teknik Üniversitesi, Edebiyat Fakültesi, Türk Dili ve Edebiyatı Bölümü, Erzurum, Türkiye. Elmek: uguruzunkaya@gmail.com https://orcid.org/0000-0003-4534-9305

** Arş. Gör., Bilecik Şeyh Edebali Üniversitesi, Fen-Edebiyat Fakültesi, Türk Dili ve Edebiyatı Bölümü, Bilecik, Türkiye.

Elmek: tumerkaraayak@gmail.com

https://orcid.org/0000-0002-2322-9663
} 
The Documents of Old Uyghur Buddhāvatainsaka-sūtra (Leaf 20, 27, 28 and 29)

\begin{abstract}
Sanskrit Buddhāvatamsaka-sütra 'flower ornament scripture' is one of the most voluminous works of Buddhism with its Huayan jing in Chinese. Buddhāvatamsaka-sūtra forms the literary basis of the Huayan school, which was developed in China and then spread to East Asia. This school is based on the idea that all the phenomena in the world are mutually interpenetration. This paper is about the fragments belonging to Old Uyghur Buddhāvatainsaka-sūtra commentary, which has not been published before. These fragments are located at the Turfan Collection in Berlin Brandenburg Sciences and Humanities, with the archive numbers U 1320 ([T I L] 3), U 1309 ([T I] 7), U 1307 ([T I] 8) ve U 1305 ([T I] 9) respectively. These fragments in question constitute the 20th, 27th, 28th, and 29th leaves of the Old Uyghur manuscript, which is a compilation of at least thirty chapters containing the text / fragments related to the Faxiang school that developed from the Yogācāra school of Buddhism. In this paper, the transcription and transliteration of aforementioned Old Uyghur fragments, translations into Turkish, notes and glossary with an analytical index are presented.
\end{abstract}

Keywords: Buddhism, Buddhāvatamisaka-sūtra, Huayan school, Old Uyghur, text edition. 


\section{Extended Summary}

This paper deals with the edition of four fragments of the Huayan school of Buddhism. The article basically consists of six parts: (1) Introduction: A Brief Outline of Buddhāvatamsaka-sūtra, (2) Framework of the Study and Method, (3) Transcription and Transliteration of Old Uyghur Text, (4) Translation of Old Uyghur Text, (5) Remarks on Old Uyghur Text, finally (6) Index-Glossary. In this extended summary, the study will be introduced in general terms.

In the chapter entitled Introduction: A Brief Outline of Buddhāvatamsakasütra, the aim is to introduce this Buddhist scripture. Sanskrit Buddhāvatamsakasūtra 'flower ornament scripture' is one of the most voluminous works of Buddhism with its Huayan jing in Chinese. Buddhāvataimsaka-sütra forms the literary basis of the Huayan school, which was emerged in China and then spread to East Asia. This school is based on the idea that all the phenomena in the world are mutually interpenetration. Only two parts from Buddhāvatamsaka-sütra in Sanskrit have survived. The first is Daśabhümika-sūtra, and the second is Gandavyūha-sūtra. This scripture has been translated three times from Sanskrit to Chinese. The first of these was carried out by Buddhabhadra（佛大跋陀 Fodabatuo) (359-429) in 421. The second translation was performed by monk Śikșānanda from Khotan（實叉難陀 Shichanantuo) in 699. The third translation was done by Prajñā (般若 Bore). It was also translated into Tibetan. Buddhāvatamsaka-sūtra essentially consists of two basic issues. One of them is "(1) eulogy of the Buddha's unique abilities and his appearance in the world as a teacher", and another is (2) "description of the bodhisattva's career." (Hamar 2014: 149).

In the chapter entitled Framework of the Study and Method, the physical properties of the fragments used in the study are defined and information about the method followed is given. This paper is about the fragments belonging to Old Uyghur Buddhāvatainsaka-sūtra commentary, which has not been published before. These fragments are preserved at the Turfan Collection in Berlin Brandenburg Sciences and Humanities, with the archive numbers U 1320 ([T I L] 3), U 1309 ([T I] 7), U 1307 ([T I] 8) and U 1305 ([T I] 9) respectively. These fragments in question constitute the 20th, 
27th, 28th, and 29th leaves of the Old Uyghur manuscript, which is a compilation of at least thirty chapters containing the fragments related to the Faxiang school that developed from the Yogācāra school of Buddhism. There are 12 lines on the recto and 12 lines on the verso of U 1320 ([T I L] 3), which forms the 20th leaf of the 20th chapter. This fragment has the pagination $y(e) g(i) r m i n c ̧$ ülüşs $y(e) g(i) r m i ~ p(a) t(a) r$ 'chapter 20, leaf $20^{\prime}$. Both sides of the fragment are damaged. The 10th line of the recto is seriously damaged. U 1309 ([T I] 7), which forms the 27th leaf of the 20th chapter, has a total of 16 lines on the recto and verso of 8 lines; however, the first five lines on the recto of the fragment could be fully preserved. The back-page of the fragment is damaged from the fifth line. This fragment has the pagination $y(e) g(i)$ rminç ülüs yeti otuz 'chapter 20, (leaf) 27'. U 1307 ([T I] 8), which forms the 28th leaf of the 20th chapter, has a total of 16 lines on the recto and verso pages of 8 lines; however, the first five lines on the recto of this fragment have been preserved as a whole, while the last lines are damaged. The back-page of the fragment is also damaged from the fifth line, and only a few letters were detected in the last line. This fragment has the pagination y(e)g(i)rminç ülüş säkiz otuz 'chapter 20, (leaf) 28'. On the front and back pages of U 1305 ([T I ] 9), which forms the 29th leaf of the 20th chapter, there are 14 lines in total; however, only a few letters could be detected in the last line of the front-page of this fragment. The back-page of the fragment was completed with some equivalent lines. This fragment has the pagination y(e)g(i)rminç ülüs tokuz otuz 'chapter 20, (leaf) 29'.

In the chapter named Transcription and Transliteration of Old Uyghur Text, the method related to the transcription and transliteration in Uigurisches Wörterbuch was followed (Röhrborn 1977-1998: 9-10 and 13-14; Röhrborn 2010: XXXIII-XXXV). In the chapter entitled Translation of Old Uyghur Text, while the Old Uyghur text was translated into Turkish, it was tried to adhere to the original text as much as possible. Since the Chinese equivalent text of this Old Uyghur text has not been identified yet, the concepts related to Buddhism and the issues related to the Turkic language have been mentioned as far as can be determined in the chapter titled Remarks on Old Uyghur Text. The index section of the paper has been prepared in an analytical context and all of the words that have been preserved in the text are included in this chapter. This article will be followed by the edition of other texts related to chapter 20 . This study aims to make a small contribution to the determination of the schools of Central Asian Turkish Buddhism and to reveal the canon of Turkish Buddhism. 


\section{Giriş: Buddhāvatamisaka-sūtra'ya Kısa Bir Bakış}

Sanskritçe Buddhāvatamsaka-sūtra 'çiçek bezeme sūtrası' ve Çincesiyle Huayan jing (華嚴經) Budizmin en hacimli eserlerinden biridir. Buddhāvatamsaka-sūtra Budizmin Çin'de oluşum gösteren ve daha sonra Doğu Asya’ya yayılan Huayan (華嚴) ekolünün de yazınsal temelini oluşturur. $\mathrm{Bu}$ ekol dünyadaki bütün olguların birbiriyle karşılıklı iç içe geçmiş olduğu düşüncesini temel alır. Buddhāvatamisaka-sūtra'nın Sanskritçesinden sadece iki bölüm günümüze ulaşmıştır. Bunlardan birincisi "Bodhisattva'nın manevi gelişimini tasvir eden Daśabhümika-sūtra" ve ikincisi "Sudhana isimli genç bir çocuğun yolu arayışıyla ilişkilendirildiği Gaṇdavyūha-sūtra"dır (Hamar 2007: 141). Bu sūtra Sanskritçeden Çinceye üç kez tercüme edilmiştir. Bunlardan ilki Buddhabhadra (佛大跋 陀 Fodabatuo) (359-429) tarafından 421'de gerçekleştirilmiştir ve bu altmışıncı fasikül Huayan jing olarak adlandırılır (krş. Chiu 2016: 55; Hamar 2007: 147-149; Hamar 2014: 149). İkinci tercüme Hotenli keşiş Śikșānanda (實叉難陀 Shichanantuo) tarafından 699'da gerçekleştirilmiş ve bu da sekseninci fasikül Huayan jing olarak bilinir (krş. Chiu 2016: 55; Hamar 2007: 149-150; Hamar 2014: 149). Üçüncü tercüme Prajñā (般若 Bore) tarafından yapılmıştır. (krş. Chiu 2016: 55; Hamar 2007: 147-149; Hamar 2014: 149). Aynı zamanda bu sūtra Tibetçeye de tercüme edilmiştir. Tibetçe tercüme, "dokuzuncu yüzyılın ilk çeyreğinde iki Hindistanlı üstat Jinamitra ve Surendrabodhi ve bir Tibetli üstat Ye-shes-sde tarafından tamamlanmıştır" (Hamar 2014: 149; ayrıca krş. Hamar 2007: 154).

Mahāyāna Budizmine ilişkin bir sūtra bir olan Buddhāvatamsaka-sūtra “Buddha'nın bodhi ağacının altında aydınlanmaya eriştiğini fark ettiği gibi, nihai gerçeğin en mükemmel izahı olarak kabul edilir” (Hamar 2014: 148; ayrıca krş. Hamar 2015: 115a; Hamar 2007: XIII). Bir terim olarak Buddhāvatamisaka, "kişinin yalnızca bir Buddha tarafından gerçekleştirilebilecek kendi bedeninin çoğaltımı mucizesinin özel bir türü anlamına gelir” (Hamar 2015: 115b). Buddhāvatamsakasūtra esasen iki temel konudan mürekkeptir. Bunlardan biri “(1) Buddha’nın yete- 
neklerini ve bir üstat olarak dünyadaki görünüşünü övme”dir ve bir diğeri de “(2) Bodhisattva'nın gidiş yolunu betimleme"dir (Hamar 2015: 115b; ayrıca krş. Hamar 2014: 149). Bu sūtranın iki ünlü bölümü olan Daśabhümika ve Gaṇ̣avyūha'da Bodhisattva uygulamalarını tasvir edilir (Hamar 2015: 115a-116b; Hamar 2014: 149). Daśabhümika, Bodhisattva'nın bütün canlıları ızdıraptan kurtarmasının on aşamasını betimler (ayrıca bk. Tokyürek 2019: 303). Bunlar şöyledir:

(1) 'Neşe' (Hamar 2015: 116a) aşaması Skt. pramuditā (Edgerton 1953: 383b), Çin. 歡喜地 huanxi di (DDB; Hirakawa 1997: 682a), EUyg. pramudit ärtiyü ögrünçü atl(l)g oron (Tokyürek 2018: 5122817-2818) karş1lı̆̆ındadır.

(2) 'Kirlilikten kurtulma' (Hamar 2015: 116a) aşaması Skt. vimalā (Edgerton 1953: 496a), Çin. 離垢地 ligou di (DDB; Hirakawa 1997: 1234a), EUyg. vimala kirsiz arıg atl(l)g oron (Tokyürek 2018: 5132826-2827) karş1lı̆̆ındadır.

(3) 'İhtişam' (Hamar 2015: 116a) aşaması Skt. prabhākarī (Edgerton 1953: 382b), Çin. 發光地 faguang di (DDB; Hirakawa 1997: 860a), EUyg. prabaykari y(a) ruțdaçı yaşutdaçı atl(l)g oron (Tokyürek 2018: 5132833-2834) karş1lı̆̆ındadır.

(4) 'Parlaklık' (Hamar 2015: 116a) aşaması Skt. arcișmatī (Edgerton 1953: 66a), Çin. 焰慧地 yanhui di (DDB), EUyg. arçişmati yalınayur bilgä bilig atl(l)g oron (Tokyürek 2018: 5142843-2844) karşıllı̆̆ındadır.

(5) 'Üstesinden gelmesi zor' (Hamar 2015: 116a) aşaması Skt. sudurjayā (Edgerton 1953: 598b), Çin. 難勝地 nansheng di (DDB; Hirakawa 1997: 1239b), EUyg. sudurçaya alpḍa yegädddäçi atl(i)g oron (Tokyürek 2018: 5152852-2853) karş1lı̆̆ındadır.

(6) 'Mevcudiyet' (Hamar 2015: 116a) aşaması Skt. abhimukhī (Edgerton 1953: 55a), Çin. 現前地 xianqian di (DDB; Hirakawa 1997: 824b), EUyg. abimuke yü̈̈z yügärü boldaçı atl(i)g oron (Tokyürek 2018: 5152860-2861) karş111ğindadır.

(7) 'Uzak seyahat' (Hamar 2015: 116a) aşaması Skt. dūraṃgamā (Edgerton 1953: 268b), Çin. 遠行地 yuanxing di (DDB; Hirakawa 1997: 1163b), EUyg. duraygama sinarkl yorlklıg atl(l)g oron (Tokyürek 2018: 515-5162867-2868) karşıllı̆ıındadır. 
(8) 'Sabitlik' (Hamar 2015: 116a) aşaması Skt. acalā (Edgerton 1953: 6b), Çin. 不動地 budong di (DDB; Hirakawa 1997: 52b), EUyg. açala täpränçsiz atl(l)g oron (Tokyürek 2018: 516 2875-2876 ) karşıllı̆̆ındadır.

(9) 'Mükemmel bilgelik' (Hamar 2015: 116a) aşaması Skt. sādhumatī (Edgerton 1953: 590b), Çin. 善慧地 shanhui di (DDB; Hirakawa 1997: 266a), EUyg. saḍmati bilgä biligtä uzanmak oron (Tokyürek 2018: 516-517 $2882-2883$ ) karşılı̆̆ındadır.

(10) 'Dharma bulutu' (Hamar 2015: 116a) aşaması Skt. dharmameghā (Edgerton 1953: 280b), Çin. 法雲地 fayun di (DDB; Hirakawa 1997: 717b), EUyg. darmamıg nom bulıt atl(l)g oron (Tokyürek 2018: 517 2890-2891 ) karş1lığındadır.

Buddhāvatamsaka-sūtra'da yer alan "imanın on aşaması (Çin. 十信 shixin)" (bk. Hamar 2015: 116a), “on ikamet yeri (Çin. 十住 shizu)" (bk. Hamar 2015: 116a), “on uygulama (Çin. 十行 shixing)” (bk. Hamar 2015: 116b) ve “faziletin on ithafı (Çin. 十迴向 shihuixiang)” (bk. Hamar 2015: 116b) gibi kavramlar da bu eserin muhtevasına ilişsin başka hususlardır.

\section{Çalışmanın Çerçevesi ve İzlenen Usul}

$\mathrm{Bu}$ çalışma daha önce yayımlanmamış Eski Uygurca Buddhāvatamisakasūtra tefsirine ait metin parçaları hakkındadır. Bugün bu fragmanlar Berlin Brandenburg Bilimler Akademisi Turfan Koleksiyonu'nda sirasiyla U 1320 ([T I L] 3), U 1309 ([T I] 7), U 1307 ([T I] 8) ve U 1305 ([T I] 9) envanter numaralarıly korunmaktadır. Bu fragmanlar Budizmin Yogācāra ekolünden gelişen Faxiang ekolüne ilişkin metin/metin parçalarının yer aldığı "en az otuz bölümden oluşan" (Özertural 2012: 14) bir derleme eser niteliğinde Eski Uygurca yazma eserin 20. bölümünün 20, 27, 28 ve 29. yapraklarını oluşturmaktadır. Berlin Turfan Koleksiyonu'nda korunan bu derleme eserin 20. bölümü K. Kitsudō'nun 2009 tarihli ve "A preliminary report on the study of the so-called Uigur Lehrtext: Chapter 20 and 21" başlıklı henüz yayınlanmamış olan yazısında tanımlanmıştır. K. Kitsudō, “20. bölümde 'donanım safhası'nın (Skt. sambhāra-avasthā) tarif edildiğini, bunun da açıkça 20. bölümde ekseriyetle atıf yapılan Buddhāvatamisakasūtra'ya yazılmış bir tefsirden tercüme edildiğini” belirtir (Özertural 2012: 14). 
20. bölümün 20. yaprağını oluşturan U 1320'nin ([T I L] 3) ön sayfasında 12, arka sayfasında da 12 satır bulunmaktadır. ${ }^{1} \mathrm{Bu}$ fragmanda $y(e) g(i)$ rminç ülüş $y(e) g(i)$ rmi p (a)t(a)r '20. bölüm, 20. yaprak' numaralandırması mevcuttur. Fragmanın her iki tarafı da hasarlıdır. Ön sayfanın 10. satırı ciddi hasar görmüştür. 20. bölümün 27. yaprağını oluşturan U 1309'un ([T I] 7) ön ve arka sayfasında 8 satırdan toplam 16 satır mevcuttur; ancak fragmanın ön yüzündeki ilk beş satıı bütünlüklü olarak korunabilmiştir. ${ }^{2}$ Fragmanın arka yüzü ise beşinci satırdan itibaren hasarlıdır. Bu fragman y(e)g(i)rminç ülüş yeti otuz ,, toĐuz üdintä bitildi '20. bölüm, 27. (yaprak), domuz zamanında yazıldı' ifadesi mevcuttur. 20. bölümün 28. yaprağını oluşturan U 1307'nin ([T I] 8) ön ve arka sayfalarında 8 satırdan toplam 16 satır bulunur; ancak bu fragmanın ön yüzündeki ilk beş satır bütünlüklü olarak korunabilmişken son satırlar hasarlıdır. ${ }^{3}$ Fragmanın arka yüzü de beşinci satırdan itibaren hasarlı olup son satırda sadece birkaç harf tespit edilebilmiş̧ir. Fragman-

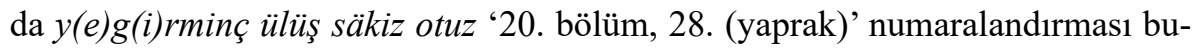
lunmaktadır. 20. bölümün 29. yaprağını oluşturan U 1305'in ([T I] 9) ön ve arka sayfalarında 7 satırdan toplam 14 satır vardır; ancak bu fragmanın ön yüzünün son satırında yalnızca birkaç harf tespit edilebilmiştir. ${ }^{4}$ Fragmanın arka yüzü bazı eş değer satıllar yardımıyla tamamlanmıştır. Fragman $y(e) g(i)$ rminç ülüş tokuz otuz '20. bölüm, 29. (yaprak)' numaralandırmasına sahiptir.

$\mathrm{Bu}$ çalışma zikredilen fragmanların çeviri yazıları ve harf çevirilerini, Türkiye Türkçesine aktarmalarını, metne ilişkin açıklamalarını ve dizin-sözlügünü içermektedir. Fragmanların çeviri yazısı ve harf çevirisinde Uigurisches Wörterbuch'da belirlenen çeviri yazısı ve harf çevirisi usulü takip edilmiştir (Röhrborn 1977-1998: 9-10 ve 13-14; Röhrborn 2010: XXXIII-XXXV). Eski Uygurca metin Türkiye Türkçesine aktarılırken mümkün mertebe orijinal metne sadık kalınmaya çalışılmıştır. Bu Eski Uygurca metnin Çince eş değer metni henüz tespit edilemediğinden açıklamalar bölümünde tespit edilebildiği kadarıyla Budizme ilişkin kavramlar ile Türk diline ilişkin meselelere değinilmiştir. Çalışmanın dizin kısmı analitik bağlamlı olarak hazırlanmıştır ve metindeki bütünlüklü olarak korunabilmiş sözcüklerin tamamı bu bölüme dahil edilmiştir. Bu yazıyı yine 20. bölüme ilişkin diğer metinlerin yayımı izleyecektir.

\footnotetext{
1 Fragmanın ayrıntılı katalog bilgisi için bk. Özertural 2012: 209, katalog nu. 251.

2 Fragmanın ayrıntılı katalog bilgisi için bk. Özertural 2012: 210, katalog nu. 252.

3 Fragmanın ayrıntılı katalog bilgisi için bk. Özertural 2012: 210-211, katalog nu. 253.

4 Fragmanın ayrıntılı katalog bilgisi için bk. Özertural 2012: 211-212, katalog nu. 254.
} 


\section{Eski Uygurca Metnin Çeviri Yazısı ve Harf Çevirisi}

U 1320 ([T I L] 3)

20. bölüm 20. yaprak

ön

(01)

\begin{tabular}{|c|c|}
\hline \multirow{2}{*}{1} & $\ldots$, , tört törlüg ülgüsü[z] $\ldots$ \\
\hline & ... l'r ,, twyrt twyrlwk 'wylqwsw/... \\
\hline \multirow{2}{*}{2} & bışrunsarlar ötrü ...... \\
\hline & pyşrwns'r l'r 'wytrw pwl/... \\
\hline \multirow{2}{*}{3} & ädgü kılınçların ävirä ... \\
\hline & 'dkw q̈ylynç l'ryn 'vyr' ... \\
\hline \multirow{2}{*}{4} & kolurlar , , iyat ...... \\
\hline & q̈wlwr l'r ,, 'yy't/ ...... \\
\hline \multirow{2}{*}{5} & larımın imrär[igmä] ...... \\
\hline & l'rymyn 'ymr'r//// ...... \\
\hline \multirow{2}{*}{6} & ažun tınl(1)g ...... \\
\hline & "ž wn tynlq 'w...... \\
\hline \multirow{2}{*}{7} & ülüg ......... \\
\hline & 'wylwk pwl... ...... \\
\hline \multirow{2}{*}{8} & küçi......... \\
\hline & kwyçy//........ \\
\hline \multirow{2}{*}{9} & $\operatorname{arınm} \ldots \ldots \ldots$ \\
\hline & "rynm......... \\
\hline \multirow[t]{2}{*}{10} & $\cdots \cdots \cdots$ \\
\hline & $\mathrm{k}^{\prime} \ldots \ldots \ldots$ \\
\hline \multirow{2}{*}{11} & pret $\mathrm{y}[1 \mathrm{lk} 1] \ldots \ldots \ldots$ \\
\hline & pryt $y / / / / \ldots \ldots \ldots$ \\
\hline \multirow{2}{*}{12} & ämgäkdin $\ldots \ldots \ldots$ \\
\hline & 'mk'k dyn ......... \\
\hline
\end{tabular}


arka

y(e)g(i)rminç ülüş y(e)g(i)rmi p(a)t(a)r, , ykrmynç 'wylwş ykrmy ptr ,,

(13) $1 \quad \ldots$, , asurelar eliginin

...yk ," "swry l'r 'ylyky nynk

(14) $2 \quad \ldots$ çambu sögüt yapırgakı

(15) $3 \quad \ldots$, , tag basguklarının

(16) $\quad \begin{aligned} & \quad \ldots \ldots \ldots \text { tütün } \\ & \ldots \ldots \ldots / \text { lwt twytwn }\end{aligned}$

(17) $5 \quad \ldots \ldots \ldots$ [bü]tgüsinä

(18) $6 \quad \ldots \ldots$ tițilmädin

(19) $7 \quad \ldots \ldots$ [ançu]layu ymä

(20) $\quad \begin{aligned} & \text { …. üzä } \\ & \quad \ldots \ldots \ldots \text { 'wyz }\end{aligned}$,

(21) $\quad 9 \quad \ldots \ldots\left[\right.$ niz] vanilar $^{5}$

(21) $\quad$..../// vn'y l'r

(22) $\quad 10 \quad \ldots \ldots \ldots$ [tö]rlüg

(23) $11 \quad \ldots \ldots \ldots$, , tokuz

(23) $11 \quad \ldots \ldots \ldots$ ss , twq̈wz

(24) $12 \quad \ldots \ldots \ldots$ üzä

U 1309 ([T I] 7)

20. bölüm 27. yaprak 
ön

(25) 1 öni öni tolp oronka yetgülük

(26) 2 ädrämlärkä tägmişkä yänä bo buyan ävirmäk

'dr'm l'rk' t'kmyş k' y'n' pw pwy'n 'vyrm'k

(27) 3 içintä kılmış buyanın tolp oronta barçada

'yçynt àylmyş pwy' nyn twlp 'wrwn t' p'rç' d'

(28) 4 tägzün ... kolmışka anın bo buyan

(29) 5 ävirmä[k] ..... k1lıp oronka yetürmäk

(29) 5 'vyrm'/ ..... q̈ylyp 'wrwn ä' yytwrm'k

(30) $6 \quad \cdots \ldots \ldots$, , bo ärür törtünç

(31) 7 ........

(31) $7 \quad \ldots \ldots \ldots / / y$ 'n 'vyrm'k,

(32) $\quad 8 \quad \cdots \ldots$ ly

arka

(33) $1 \quad$ b(ä)lgürmiş ,, täyäşisiz yöläşürügsüz 1dok

y(e)g(i)rminç ülüş yeti otuz ,, toyuz üdintä bitildi ,, ykrmynç 'wylwş yyty 'wtwz ,, twnkwz 'wydynt' pytyldy ,,

(34) 2 kutlug yer oronlar ärsär ,, kim anta bilgä

(35) 3 biliglig $1 \operatorname{dok}^{7}$ burhanlar, , burhan kutın bulmışların

(35) 3 pylyklyk 'ydwä pwrq'n l'r ,, pwrq'n q̈wtyn pwlmyş l'ryn

(36) 4 körkitip ,, nomlug tilgän ävirip ulug küü

(36)

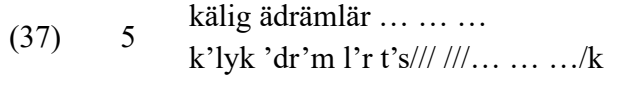

(38) $6 \quad \begin{aligned} & \text { burhanlar işin ......... } \\ & \text { pwrq'n l'r 'yşyn ......... }\end{aligned}$

(39) $7 \quad \begin{aligned} & \text { lar ärsär , }, \ldots \ldots \ldots \\ & \text { l'r 'rs'r ,, } \ldots \ldots \ldots\end{aligned}$

(40) $8 \quad$ etig $\ldots \ldots \ldots$

$6<1>$ harfinin çengeli yazılmamıștır.

7 Sözcük satırın üstüne yazılmıştır. 
U 1307 ([T I] 8)

20. bölüm 28. yaprak

ön
(41)
sakışsız nomlar yalyuz bir nomda tutulmışın
1 s'äyşsyz nwm l'r y'lnkwz pyr nwmd' twtwlmyşyn
2 bylk' ly 'wywr, ,'wyçwnç pwrq'n l'r dyn 'şydmyş
3 nomug unitmaksız bulur, , törtünç burhan-
nwmwq 'wnytm' ̈̈syz pwlwr ,, twyrtwnç pwrq'n
4 lar y(a)rlıkamış ürtüglüg ${ }^{8}$ kizläklig nomlarnıy
l'r yrlyä'myş 'wyrtwklwk kyz l'klyk nwm l'r nynk
arka

(49) 1 üläyürlär ,, köni nom ${ }^{9}$ törö tuttururlar ${ }^{10}, \mathrm{k}($ ä)ntü-

y(e)g(i)rminç ülüş säkiz otuz

ykrmynç 'wylwşs s'kyz 'wtwz

'wyl'ywr l'r , kwyny nwm twyrw twttwrwr l'r ,, kntw

(50) 2 läri yalıuzın bir kuşatrelıg ak bolup

l'ry y'lnkwz yn pyr kwş'try lyq "q pwlwp

(51) 3 kayudın sınar ugrasar, , ol yınakdınkı

ä'yw dyn synk'r 'wqr's'r ,, 'wl yynk'ädynäy

(52) 4 iş küdüglärin tıdıgsız $a$ dasız bütürür-

'yş kwydwk l'ryn tydyqsyz '/d'syz pwytwrwr

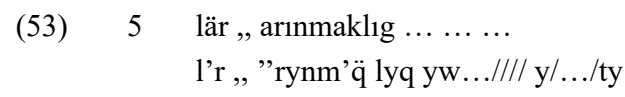

8 Sözcüğün ilk iki harfi <'w> satırın altına yazılmıştır.

9 Sözcük satırın üstüne yazılmıştır.

10 Sözcükte yer alan üçüncü sıradaki $<\mathrm{t}>$ satırın üstüne yazılmıştır. 
(54) 6 üzä başların .........

'wyz ' p'ş l'ryn .........k

(55) $7 \quad \operatorname{lig} \operatorname{cog} \ldots \ldots \ldots \ldots$

lyk çwq

(56) $8 \quad \operatorname{l'r} \ldots \ldots \ldots$

l'r ...........

U 1305 ([T I] 9)

20. bölüm 29. yaprak

ön

(57) 1 lag tınl(1)glarig b(ä)kintin (oku: bagıntın) bukagusıntın

l'q tynlq l'ryq pkyntyn pwä'qwsyntyn

(58) 2 kutgarurlar, , yazmış yajılmış kişi

q̈wtq'rwr l'r ,, y'z myş y'nkylmyş kyşy

(59) 3 lärig yazukıntın boşuyurlar , ölümçi

l'ryk y'z wäyntyn pwşwywr l'r ,, 'wylwmçy

(60) 4 tınl(1)glarıg isig özlärin yolug barıp tynlq l'ryq 'ysyk 'wyz l'ryn ywlwq p'ryp

(61) 5 ölümintin [oz]gururlar, , takı ymä kim'wylwmyntyn /// qwrwr l'r, , t'äy ym' kym

(62) 6 lär $\operatorname{bir}[0 ̈ \mathrm{k}] \ldots$.... tutşı tügmä l'r pyr/// ... ...wn twtşy twykm'

(63) 7

.......... nyn

arka

(64) $1 \quad$ b(ä)kütgükä eyin bolurlar,, terinintä pkwtkw k' 'yyyn pwlwr l'r ,, tyrynynt'

(65) 2 kuvragınta uz yıgınmak üzä ädgü yiltizq̈wvr'qynt' 'wz yyqynm'ä 'wyz ' 'dkw yyltyz

(66) 3 lärig b(ä)kütgükä eyin bolurlar ,, äd l'ryk pkwtkw k' 'yyyn pwlwr l'r ,, 'd

(67) 4 tavar yevägintä uz yıgınmak üzä ädgü t'v'r yyv'kynt' 'wz yyqynm'ä 'wyz' 'dkw

(68) 5 yiltizlärig b(ä)kütgükä [eyin] bolurlar,, yyltyz l'ryk pkwtkw k' //// pwlwr l'r, , 
(69) 6 buşı bermäkdä $u z$ [yıgınmak üzä] ädgü pwşy pyrm'k d' 'wz /////////// / 'dkw

(70) $\quad 7 \quad$ yiltizl[ärig b(ä)kütgükä eyin bolurlar] yyltyz $/ / / / /$ //I// // //I// //// //

\section{Eski Uygurca Metnin Türkiye Türkçesine Aktarması}

U 1320 ([T I L] 3) (ön)

(1) ... dört türlü sayısız ... (2) öğrenseler sonra ... (3) sevaplarını çevirerek ... (4) isterler. Utanma ... (5) ... bütün ... (6) hayat şeklindeki canlı ... (7) pay ... (8) gücü ... (9) temizlenm[ek]... (10) ... (11) aç ruh (Skt. preta), hayvan ... (12) sikıntıdan ...

\section{U 1320 ([T I L] 3) (arka)}

[yirminci bölüm, yirminci yaprak] (1) ... şeytanlar (Skt. asura) hanının (2) ... elma (Skt. jambu) ağacı yaprağı (3) ... dağ kitlelerinin (4) ... duman (5) ... ikmaline (6) ... terkedilmeden (7) ... bu şekilde de (8) ... ile (9) ... hirslar (Skt. kleśa) (10) ... türlü (11) ... dokuz (12) ... ile

U 1309 ([T I] 7) (ön)

(1) başka başka her yere yetecek (2) faziletlere ulaşmışa yine bu sevabın tevcihi (3) içinde işlenmiş sevabını her yerde tamamen (4) ulaşsın. Arzu edilene bu yüzden bu sevabın (5) tevcihi ... işleyerek yere ulaştırma (6) ... dördüncü budur (7) ... sevabin tevcihi (8) ...

U 1309 ([T I] 7) (arka)

[yirminci bölüm, yirmi yedinci (yaprak), domuz vaktinde yazıldı] (1) ortaya çıkmış. Benzersiz ${ }_{2}$ kutsal $_{2}$ (2) yerler ${ }_{2}$ ise, öyle ki orada bilgelik ${ }_{2}$ (3) kutsal Buddhalar, Buddha kutsallığına eriştiklerini (4) gösterip öğretili tekerleği çevirerek çok büyülü (5) faziletler ... (6) Buddhalar işini ... (7) ... ise, ... (8) donanım ...

U 1307 ([T I] 8) (ön)

(1) sayısız öğretiler ancak bir öğretide tutulduğunu (2) bilirler. Üçüncü: Buddhalardan işitmiş (3) öğretiyi unutmaksızın bulurlar. Dördüncü: Buddhalar[ın] (4) buyurduğu gizli ${ }_{2}$ öğretilerin (5) usul 2 ünü ... olur. Beşinci: O öğreti (6) ... kör olduğunu (7) ... gökyüzü ${ }_{2}(8) \ldots$ Altınc1: 


\section{U 1307 ([T I] 8) (arka)}

[yirminci bölüm, yirmi sekizinci (yaprak)] (1) paylaştırırlar. Hakiki öğre$\mathrm{ti}_{2}$ tuttururlar. Kendileri (2) yalnızca Buddhanın bir gölgeliği ak olup (3) hangi taraftan niyetlenirse, o yöndeki (4) işleri ${ }_{2}$ engelsiz [ve] tehlikesiz tamamlarlar. (5) Temizlenme ... (6) ile başlarını ... (7) parıltı ... (8) ...

U 1305 ([T I] 9) (ön)

(1) ... canlıları bağ $\breve{g}_{2}$ ndan (2) kurtarırlar. Hata işlemiş kişileri (3) suçundan serbest bırakırlar. Ölmek üzere olan canlıların sıcak bedenleri yolu gidip (5) ölümünden kurtulurlar. Yine (6) her kim ... daima bağlamak... (7) ...

U 1305 ([T I] 9) (arka)

[yirminci bölüm, yirmi dokuzuncu (yaprak)] (1) zincire uygun davranırlar. (2) Topluluk 2 ta iyi yoğunlaşma dolayısıyla iyi esasları (3) zincire uygun davranırlar. (4) Mal mülk donatımında iyi yoğunlaşma dolayısıyla iyi (5) esasları zincire [uygun] davranırlar. Sadaka vermede iyi [yoğunlaşma dolayısıyla] iyi (7) esas[ları zincire uygun davranırlar.]

\section{Eski Uygurca Metne İlişkin Açıklamalar}

(11) pret: EUyg. pret ifadesi Soğd. pr'yt (Gharib 1995: 281b, 7029. madde), Toharcanın A diyalektinde pret (Poucha 1955: 202) ve Toharcanın B diyalektinde prete (Adams 2013: 452) olarak tanıklanmış olup kökeni itibariyle Skt. preta'ya dayanır. Skt. preta 'hayalet, aç ruh' anlamındadır (Monier-Williams 1899: 711c).

(13) asure: EUyg. asure ifadesi Toharcanın A diyalektinde asur (Poucha 1955: 13), Toharcanın B diyalektinde asūre (Adams 2013: 35) ve āsūre (Adams 2013: 64) olarak tanıklanmıştır ve kökeni itibariyle Skt. asura'ya dayanmaktadır. Skt. asura 'şeytan’ anlamındadır (Monier-Williams 1899: 121a; Rhys Davis-Stede 1921-25: 89).

(14) çambu: EUyg. çambu, Skt. jambu 'kırmızı elma ağacı' karşılığındadir (Monier-Williams 1899: 412b; Rhys Davis-Stede 1921-25: 277).

(15) basguk+larınıy: Erdal, basguk ifadesinin Mani yazılı bir metnin tanıklığında başgok yahut başkok şeklinde okunabileceğini belirtir (1991: 158159). Burada bas- fiilinden hareketle bas-guk yapısı esas alınmıştır, ayrıca krş. 
tag basgukınça Tezcan 1974: 44 ${ }_{363}$; t(a)vgaç uluşk[a] basguk Röhrborn 1991: 53483-484.

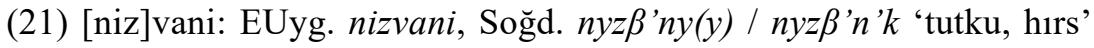
sözcüğüne dayanır (Gharib 1995: 255b, 6371. madde) ve Skt. karşıllğı ise kleśa'dır ve yine 'hırs, tutku' anlamlarındadır (Monier-Williams 1899: 324a; Edgerton 1953: 198a).

(26) buyan ävirmäk: EUyg. buyan 'sevap', Skt. punya 'uğurlu, hoş, iyi, erdemli, değerli, kutsal' karş1lığındadır (Monier-Williams 1899: 632a). buyan ävirmäk 'sevabın tecvihi' ifadesi için bk. Tekin 1966: 390-391.

(33) tänäşisiz: Sözcügün yapısı täy+ä-ş-i+siz 'benzersiz, karşılaştır1lamaz' şeklinde açıklanabilir. Erdal, täy ‘düzey’ sözcügünün mecazen zihnin 'temkinli' hâli olarak kullanıldığını belirtir (1991: 174). İsimden fiil yapma eki $\{+\mathrm{A}-\}$ ile $t \ddot{y} \eta+\ddot{a}$ - fiili 'paha biçmek, eşit değer biçmek' anlamına gelir (Erdal 1991: 424) ve üzerine aldığı işteş çatı \{-(X)ş-\} ile täy+ä-ş- 'bir başkasına denk olmak' (Erdal 1991: 569; Clauson 1972: 526b; Nadalyayev vd. 1969: 552a) anlamı kazanır. $t a ̈ \eta+\ddot{a}-s-$ fiili $\{+\mathrm{I}\}$ fiilden isim yapma eki ile $t \ddot{a} \eta+\ddot{a}-s ̧-i$ 'uygun, eşit' (Erdal 1991: 343) anlamındadır ve Erdal, $\{+I\}$ ekinin bir zarf yapısında değil sıfat yapısında olduğunu (1991: 137) belirtir.

(33) yöläşürügsüz: Sözcüğün yapıs1 yölä-ş-ür-üg+süz 'benzersiz, karş1laştırılamaz' şeklinde açıklanabilir. yölä- 'desteklemek, destek olmak' (Erdal 1991: 630; Clauson 1972: 919b) fiilinin üzerine gelen işteş çatı $\{-(X)$ ş- $\}$ ile sözcük ‘benzemek' anlamı kazanmıştır (Erdal 1991: 574; Clauson 933a), Erdal yölä- ile yöläş- arasındaki anlamsal ilginin bir Sanskritisizm gibi anlaşıldığını belirtir (1991: 574). yöläş- üzerine gelen ettirgen çatı \{-Ur-\} ile oluşan yöläşürfiilinin üzerine gelen $\{-(\mathrm{X}) \mathrm{g}\}$ fiillden isim yapma ekiyle oluşan yöläşürüg sözcüğü ‘benzetme, karşılaştırma, kıyas' (Erdal 1991: 219; Kara-Zieme 1976: 102b) anlamına gelmektedir. Metinde täyäşisiz yöläşürrügsüz 'benzersiz 2 , karş1laştırılamaž' bir ikileme olarak kullanılmaktadır.

(36-37) küü kälig ädrämlär: Bu ifade için ayrıca krş. küü kälig ädrämin çapturgalı udı Röhrborn 1991: 54500-501.

(44) ürtüglüg kizläklig ‘örtülü, ${ }_{2}$ gizli, 'ikilemesi için bk. Ölmez 2017: 300. 
(50) kuşatre+lig: EUyg. kuşatre sözcüğü Toharcanın B diyalektinde $k s ̦ a \bar{t}(t) r e(\sim k(u) s ̦ a \overline{t r e})$ 'şemsiye' olarak tanıklanmıştır (Adams 2013: 260) ve sözcük Skt. chattra' ya dayanır (Monier-Williams 1899: 404a).

(57) b(ä)kintin (oku: bagıntın) bukagusıntın: Burada b(ä)kintin ifadesi bagıntın yahut da $b(a)$ gıntın şeklinde düzeltilerek okunmalıdır; zira EUyg. $b(a ̈)$ $k$ 'sağlam, sıkı, berk' anlamlarında olup metindeki bağlamla uyuşmamaktadır (fakat yine krş. b(ä)k bukagulukta 'sıkıca kapalı zindan' Wilkens 2007: 2423120). Bununla birlikte $b(\ddot{a}) k$ burada bukagu'nun 'zincir, bağ' bir sıfatı olmaktan çok eş anlamlı bir sözcük, bir ikileme unsuru olarak görünmektedir, nitekim EUyg.'da görülen ikilemelerin çoğunda olduğu gibi burada da her iki sözcüğe aynı ekler getirilmiştir. bag bukagu 'bağ, bukağı' ikilemesi için bk. Ölmez 2017: 255.

(69) $u z$ [yıgınmak üzä]: Tamamlama bütünüyle 65. satıra göredir.

(70) ädgü yiltizl[ärig b(ä)kütgükä eyin bolurlar]: Tamamlama bütünüyle 65-66. satırlara göredir.

\section{Dizin ve Sözlük}

\section{A}

adasız 'tehlikesiz' tıdıgsiz a. bütürürlär 52

ak 'ak, beyaz' bir kuşatrelıg a. bolup 50

al 'usul, metot' $a .+$ In [altag] ln 'usul, metot $_{2}$ ' $a .+$ in [altag] $ı n 45$

[altag] 'usul, metot' alın $a .+$ in 'usul, , metot $_{2}$ ' alın [a.+]

altıç 'altınc1' ... a. 48

[ançu]layu 'bu şekilde, böylece' ... a. ymä 19

anın 'bu sebeple' a. bo buyan ävirmä[k] 28

anta 'orada' kim a. bilgä biliglig ıdok burhanlar 34

arın- 'temizlenmek' $a .-m$... 9

arınmaklig 'temizlenme' $a$. ... 53

asure $<<$ Skt. asura 'ş̧eytan' a. +lar eliginin 13

ažun $<$ Soğd. "žwn, 'zw'n(h) 'hayat şekli' a. $\operatorname{tinl}(l) g$... 6 
B

bar- 'gitmek, varmak' yolug b.-lp 60

barça 'bütün, tamamen' tolp oronta b. + da tägzün 27

basguk 'dağ kitlesi' tag b. +larını 15

baş 'baş' üzä $b .+$ ların ... 54

b(ä)k (okuma düzeltmesi: bag) 'bağ, zincir, bukağı' b. + intın bukagusintın 57

b(ä)kütgü, [b(ä)kütgü] 'zincir' b. + kä eyin bolurlar $64,66,68,70$

b(ä)lgür- 'ortaya çıkmak' b.-miş 33

bermäk 'verme' buşı $b .+d \ddot{a} 69$

beşinç 'beşinci' b. ol nom 45

bışrun- 'öğrenmek' b.-sarlar ötrü ... 2

bil- 'bilmek' bir nomda tutulmışın b.-gäli uyurlar 42

bilgä 'bilge' $b$. biliglig 'bilgelik' b. biliglig ıdok burhanlar 34

biliglig 'bilgili' bilgä $b$. 'bilgelik' bilgä $b$. ıdok burhanlar 35

bir 'bir' b. kuşatrelıg ak bolup 50; b. nomda tutulmışın 41

bir[ök] 'fakat' $b . \ldots 62$

bo 'bu' b. 26, 28, 30; b. ärür törtünç 30; anın b. buyan ävirmä $[k]$... 28; yänä b. buyan ävirmäk içintä kılmış 26

bol-, bol- 'olmak' b.-ur 45; b(ä)kütgükä eyin b.-urlar 64, 66, 68, 70; bir kuşatrelig ak b.-up 50

boşu- 'serbest bırakmak, azat etmek' kişilärig yazukıntın b.-yurlar 59

bukagu 'bağ, bukağ1, zincir' bagintın b. + sintın 57

bul- 'edinmek, bulmak' burhan kutın b.-mışların körkitip 35; burhanlardın äşidmiş nomug unıtmaksız b.-ur 43

burhan < Çin. 佛 fo 'Buddha' ve Tü. han 'Buddha' b.+lardın äşidmiş nomug 42; b. +lar işin ... 38; b. +lar y (a) rlıkamış 43; bilgä biliglig ıdok b. +lar 35; burhan kutın bulmışların b. 35

buş $1<$ Çin. 布施 bushi 'sadaka' b. bermäkdä 69

buyan, [bu]yan $<<$ Skt. punya 'sevap' $b$. ävirmäk 26, 28, 31; b.+ ın tolp oronta barçada tägzün 27

[bü]tgü 'ikmal, tamamlama' ... b. + sigä 17

bütür- 'tamamlamak' tıdıgsız adasız b.-ürlär 52 
Ç

çambu < Skt. jambu 'elma' ç. sögüt yapırgakı 14

çog 'parılttı, 1şık' ç. ... 55

E

elig 'han' asurelar e.+inin 13

etig 'donanım, süs' e. ... 40

eyin, [eyin] '(bol- ile) uygun (davranmak)' b(ä)kütgükä e. bolurlar 64, $66,68,70$

\section{$\ddot{\mathrm{A}}$}

äd 'mal, mülk' ä. tavar 66

ädgü 'iyi’ ä. kllınçların 3; ä. yiltizlärig 65, 67, 69

ädräm 'fazilet' kälig ä.+lär ... 37; yetgülük ä. +lärkä tägmişkä 26

ämgäk 'sıkıntı, eziyet' $\ddot{a}$. + din $\ldots 12$

är- 'yardımc1 eylem, -dIr; olmak, var olmak, mevcut olmak' ä.-sär 39; bo

ä.-ür törtünç 30; [t] äglök ä.-țükin 46; 1dok kutlug yer oronlar $\ddot{a}$.-sär 34

äşid- 'işitmek, duymak' burhanlardın ä.-miş nomug 42

ävir-, ävir- 'çevirmek, tevcih etme’ ädgü k1lınçların $\ddot{a}$.-ä 3; nomlug tilgän

ä.-ip 36

ävirmäk, ävirmä[k] 'çevirme, tevcih etme' buyan ä. 26, 29, 31

I

1dok 'kutsal' 1. burhanlar 35; l. kutlug yer oronlar 33

1yat 'utanma' $l$.... 4

i

içintä 'içinde' buyan ävirmäk i. kılmıļ 27

imrär[igmä] 'bütün' $i . \ldots 5$

isig 'sıcak' $i$. özlärin 60

iş 'iş’ i. küdüglärin 52; burhanlar i. +in ... 38

K

kalık 'gökyüzü' ... kök $k$. 'gökyüzü,' 47

kayu 'hangi' $k$. + din sigar 51

kälig 'gelme' ulug kü̈̈ $k$. ädrämlär 37

$\mathrm{k}(\mathrm{ä}) \mathrm{ntü}$ 'kendi' $k$. + läri 49 
k1l- 'işlemek, yapmak' ... k.-ıp oronka yetürmäk 29; bo buyan ävirmäk içintä k.-mış 27

k1lınç 'amel, davranış’ ädgü $k$. +ların 'sevap, iyi amel' 3

kim ‘öyle ki; her kim’ $k$. anta bilgä biliglig 34; $k$. +lär bir [ök] ... 61

kişi 'kişi' k.+lärig yazukıntın boşuyurlar 58

kizläklig 'gizli, örtülü' ürtüglüg $k$. 'örtülü ${ }_{2}$, gizli 2 ' ürtüglüg k. nomlarnıy 44

kol- 'dilemek, istemek' k.-mışka anın bo buyan ävirmä[k] 28; k.-urlar ... 4

kök 'gök, gökyüzü' $k$. kalık 'gökyüzü ' 47

köni ‘doğru, gerçek' $k$. nom törö 49

körkit- 'göstermek' burhan kutın bulmışların k.-ip 36

kuşatrelıg $<<$ Skt. chattra 'Buddha'nın gölgeliği, şemsiye, örtü’ ve Tü. lıg 'gölgelikli, şemsiyeli' yalyuzın bir $k$. ak bolup 50

kut 'kutsallık' burhan $k$. + ın bulmışların körkitip 35

kutgar- 'kurtarmak' tınl(l)glarlg b(ä)kintin bukagusıntın k.-urlar 58

kutlug 'kutsal' ıdok $k$. 'kutsal,' 1dok k. yer oronlar 34

kuvrag 'topluluk' terinintä $k .+$ ınta 'topluluk ${ }_{2}$ ' 65

küç 'güç' $k .+i \ldots 8$

küdüg 'iş’ iş $k$. + lärin 52

küü 'ün, şan, şöhret, (metinde kälig ile) büyülü' ulug k. kälig 36

$\mathbf{N}$

[niz]vani < Soğd. nyz $\beta$ 'ny(y) 'hırs' ... n. +lar 21

nom < Soğd. nwm 'öğreti' beşinç ol $n$. ... 45; burhanlardın äşidmiş $n .+u g$ 43; köni n. törö tuttururlar 49; sakışsız n. +lar 41; ürtüglüg kizläklig $n$. +larnıり alın 44; yalyuz bir $n .+$ da tutulmışın 41

nomlug 'öğretili' n. tilgän ävirip 36

$\mathbf{O}$

ol 'o' o. yııakdınkı iş küdüglärin 51; beşinç o. nom 45

oron 'yer' o. +ka yetürmäk 29; buyanın tolp o. +ta barçada tägzün 27;

kutlug yer o. +lar ärsär 34; öyi öyi tolp o. +ka yetgülük 25

[oz]gur- 'kurtarmak' ölümintin o.-urlar 61

$\ddot{\mathbf{O}}$

ölüm ‘ölüm’ ö. +intin [oz]gururlar 61 
ölümçi ‘ölmek üzere olan, ölecek’ ö. tınl(l)glarıg 59

öni 'başka' ö. ö. tolp oronka yetgülük 25

ötrü 'sonra' bışrunsarlar $\ddot{o}$. ... 2

öz 'beden, vücut' isig $\ddot{o} .+$ lärin 60

P

pret $<$ Soğd. pr 'yt, Toh. A pret $<$ Skt. preta 'aç ruh' p. y[llkı] ... 11

S

sakışsız 'sayısız' s. nomlar 41

siyar 'taraf' kayudin s. ugrasar 51

sögüt 'ağaç' ... çambu s. yapırgakı 14

T

tag 'dağ' t. basguklarının 15

tak1 've, dahi' t. ymä kimlär bir[ök] 61

tavar 'mal, mülk' äd $t .67$

täg- 'değmek, ulaşmak' buyanın tolp oronta barçada t.-zün 28; oronka yetgülük ädrämlärkä t.-mişkä 26

[t]äglök 'kör' $t$. ärṭükin 46

täyäşisiz 'benzersiz, karşılaştırılamaz' $t$. yöläşürügsüz 'benzersiz, $t$. yöläşürügsüz ıdok kutlug yer 33

terin 'topluluk' t. +intä kuvragınta 'topluluk, 64

tıdigsız 'engelsiz' t. adasız 52

tınl(1)g 'canlı' t. +larıg 57; ažun t. ... 6; ölümçi t.+larıg 60

tilgän 'tekerlek' nomlug t. ävirip 36

tițil- 'terkedilmek' ... t.-mädin 18

tokuz 'dokuz' ...t. 23

tolp 'bütün, hep' t. oronka yetgülük 25; t. oronta barçada tägzün 27

[tö]rlüg 'türlü' ...t. 22 ; tört t. ülgüsü[z] ... 1

törö 'öğreti, yasa' nom t. 'öğreti ${ }_{2}$ köni nom t. tuttururlar 49

tört 'dört' $t$. törlüg ülgüsü[z] ... 1

törtünç 'dördüncü' $t$. 43; bo ärür $t .30$

tutş1 'devamlı' t. tügmä 62

tuttur- 'tutturmak' köni nom törö t.-urlar 49 
tutul- 'tutulmak' bir nomda t.-mışın 41

tüg- 'bağlamak' ... tutşı t.-mä 62

tütün 'duman' ...t. 16

U

u- 'muktedir olmak' bir nomda tutulmışın bilgäli u.-yur 42

ugra- 'niyetlenmek' kayudın sıyar u.-sar 51

ulug 'büyük' u. küü kälig ädrämlär ... 36

unıtmaksız 'unutmaksızın' burhanlardın äşidmiş nomug u. bulur 43

uz, uz 'iyi' buşı bermäkdä u. [yılgınmak] 69; äd tavar yevägintä u. yıgınmak 67; terinintä kuvragınta u. yıgınmak 65

$\ddot{\mathbf{U}}$

üçünç 'üçüncü’ $\ddot{u} .42$

ülä- 'paylaştırmak' ü.-yürlär 49

ülgüsü[z] 'sayısız' tört törlüg $\ddot{u} .1$

ülüg 'pay, hisse' $\ddot{u}$. ... 7

ürtüglüg 'gizli, örtülü, saklı' $\ddot{u}$. kizläklig ‘örtülü ${ }_{2}$, gizli ${ }_{2}$ ü. kizläklig nomlarnin 44

üzä, [üzä] 'ile, dolayısıyla' ü. başların ... 54; ... ü. 20, 24; äd tavar yevägintä uz yıgınmak ü. 67; buşı bermäkdä uz [yıgınmak ü.] 69; terinintä kuvragınta uz yıgınmak ü. 65

Y

yalıuz 'ancak, yalnız, tek' k(ä)ntüläri y.+ın bir kuşatrelıg ak bolup 50; sakışsız nomlar y. bir nomda 41

yạıl- 'yanılmak, hata etmek' yazmış $y$.-mış 'yanılmak,' 58

yapırgak 'yaprak' $y .+\imath 14$

y(a)rlıka- 'emretmek, buyurmak' $y$.-mış 44

yaz- 'yanılmak, hata etmek' $y$.-mış yayılmış 'yanılmak 2 'y.-mış yayılmış kişilärig 58

yazuk ‘suç, günah' y. +ıntın boşuyurlar 59

yänä 'yine' y. bo buyan ävirmäk 26

yer 'yer' $y$. oronlar 'yer, ' 1dok kutlug y. oronlar 34

yet- 'yetmek, erişmek' öyi öyi tolp oronka y.-gülük 25 
yetürmäk 'ulaştırma' oronka y. 29

yeväg 'donatım, teçhizat' äd tavar y. +intä uz yıgınmak 67

yıgınmak, [yıgınmak] 'yoğunlaşma, konsantrasyon' buşı bermäkdä uz [y.] 69; äd tavar yevägintä uz y. 67; terinintä kuvragınta uz y. 65

$\mathrm{y}[1 \mathrm{kk1}]$ 'hayvan' pret y. 11

yııakdınk1 'yöndeki' $y$. iş küdüglärin 51

yiltiz 'kök, esas' ädgü y.+lärig 65, 68, 70

ymä 'yine, dahi' ... [ançu]layu y. 19; takl y. kimlär bir[ök] 61

yol 'yol' $y .+u g$ bartp 60

yöläşürügsüz 'benzersiz, karş1laştırılamaz' täyäşisiz y. 'benzersiz, täyäşisiz y. ıdok kutlug yer oronlar 33

\section{Sonuç}

Eski Uygur edebiyatı temelde Budizm, Manihaizm ve Nasturi Hristiyanlığa ilişkin eserlerin tercümesine dayanmaktadır. Bunlar içinde de en büyük yazınsal kaynağı Budist eserler oluşturmaktadır. Budizmin en hacimli eserlerinden biri olan Sanskritçe Buddhāvatamsaka-sūtra 'çiçek bezeme sūtrası' ve Çincesiyle Huayan jing (華嚴經) Çin'de oluşum gösteren Huayan (華嚴) ekolünün temelini oluşturur. Eski Uygurca Buddhāvataṁsaka-sūtra tefsirine ilişkin dört fragmanın neşri temelinde 70 satır tespit edilmiştir. Çalışmada ele alınan fragmanlardan dizin bölümünde 143 madde başı tespit edilmiş olup bunlardan da 29'u fiil türündedir. Ayrıca söz varlığından on sözcüğün ise ödünçlenmiş olduğu görülmektedir. Türk Budizminde mevcut olan Budist ekollerinin tespiti ve Türkçe Budist külliyatın sınırlarının çizilebilmesinde bu çalışmanın katkı sağlayacağı açıktır. 


\section{Kisaltmalar}

AdW

AKDTYK

BBAW

bk.

BT

Çin.

DDB

EUyg.

krş.

nu.

SGKAO

Skt.

Soğd.

TDK

VdSUA

ZAGA
Akademie der Wissenschaften

Atatürk Kültür, Dil ve Tarih Yüksek Kurumu

Berlin-Brandenburgische Akademie der Wissenschaften

bakınız

Berliner Turfantexte

Çince

Digital Dictionary of Buddhism

Eski Uygurca

karşılaştırınız

numara

Schriften zur Geschichte und Kultur des Alten Orients

Sanskritçe

Soğdca

Türk Dil Kurumu

Veroffentlichungen der Societas Uralo-Altaica

Zentralinstitut für Alten Geschichte und Archäologie 


\section{Kaynakça}

Adams, Douglas Q. (2013), A Dictionary of Tocharian B. Revised and Greatly Enlarged. Vol. 1-2, Amsterdam \& New York: Rodopi. (Leiden Studies in Indo-European. 10.)

Chiu, King Pong (2016), Thomé H. Fang, Tang Junyi and Huayan Thought: A Confucian Appropriation of Buddhist Ideas in Response to Scientism in Twentieth-Century China, Leiden \& Boston: Brill. (Modern Chinese Philosophy. 8)

Clauson, Sir Gerard. (1972), An Etymological Dictionary of Pre-Thirteenth-Century Turkish, Oxford: Oxford at the Clarendon Press.

Edgerton, Franklin. (1953), Buddhist Hybrid Sanskrit Grammar and Dictionary, c. II: Dictionary, New Haven: Yale University Press.

Erdal, Marcel (1991), Old Turkic Word Formation. A Functional Approach to the Lexicon. Vol. I-II, Wiesbaden: Harrassowitz. (Turcologica 7.)

Gharib, B. (1995), Sogdian Dictionary: Sogdian-Persian-English, Tehran: Farhangan.

Hamar, Imre (2007), "The History of the Buddhāvatamsaka-sūtra: Shorter and Langer Texts", Reflecting Mirrors: Perspectives on Huayan Buddhism, Wiesbaden: Harrassowitz Verlag: 139-167. (Asiatische Forschungen. 151)

Hamar, Imre (2014), "Huayan Explorations of the Realm of Reality", The Wiley-Blackwell Companion to East and Inner Asian Buddhism, ed. Mario Poceski, Blackwell Publishing: 145-165.

Hirakawa, Akira. (1997), A Buddhist Chinese-Sanskrit Dictionary, Tōkyō: Reiyukai.

Kara, Georg - Zieme, P. (1976), Fragmente tantrischer Werke in uigurischer Übersetzung, Berlin: Akademie-Verlag. (AdW der DDR. ZAGA. SGKAO. BT. 7.)

Monier-Williams, Monier (1899), A Sanskrit-English Dictionary, Oxford: Oxford University Press.

Nadalyayev, V. M. - Nasilov, D. M. - Tenişev, E. R. - Şçerbak, A. M. (1969), Drevnetyurkskiy Slovar'. Leningrad: Izdat. Nauka, Leningradskoe Otd. (Akademiya Nauk SSSR. Institut Yazıkoznaniya).

Ölmez, Mehmet (2017), "Eski Uygurca İkilemeler Üzerine”, Türk Dili Araştırmaları Yı1lığı - Belleten, C. 65, S. 2, s. 243-311.

Özertural, Zekine (2012), Alttürkische Handschriften Teil 16: Mahāyāna-sūtras und Kommentartexte, Stuttgart: Franz Steiner. (Verzeichnis der Orientalischen Handschriften in Deutschland. XIII, 24.)

Poucha, Pavel (1955), Institutiones Linguae Tocharicae. Pars I: Thesaurus Linguae Tocharicae Dialecti A, Praha: Statni Pedagogicke Nakladatelstvi. (Monografie Archivu Orientalniho. XV.) 
Rhys Davids, T. W. - Stede, W. (1921-1925), The Pali Text Society’s Pali-English Dictionary, Oxford: Pali Text Society.

Röhrborn, Klaus (1977-1998), Uigurisches Wörterbuch. Sprachmaterial der vorislamischen türkischen Texte aus Zentralasien, 1-6. Wiesbaden: Steiner.

Röhrborn, Klaus (1991), Die alttürkische Xuanzang-Biographie VII. Nach der Handschrift von Leningrad, Paris und Peking sowie nach dem Transkript von Annemarie von Gabain hrsg., übersetzt und kommentiert, Wiesbaden: Harrassowitz. (Xuanzangs Leben und Werk. 3. VdSUA. 34.)

Röhrborn, Klaus (2010), Uigurisches Wörterbuch. Sprachmaterial der vorislamischen türkischen Texte aus Zentralasien, Neubearbeitung, I. Verben. Band. 1: ab- - äzügläStuttgart: Steiner.

Tekin, Şinasi (1966), “Buyan Evirmek (Sevâbın Tevcihi)”, Reşid Rahmeti Arat İçin, Ankara: Türk Kültürünü Araştırma Enstitüsü Yayınları, s. 390-411.

Tezcan, Semih (1974), Das uigurische Insadi-Sūtra, Berlin: Akademie-Verlag. (AdW der DDR. ZAGA. SGKAO. 6. BT. 3.)

Tokyürek, Hacer (2018), Altun Yaruk Sudur IV. Tegzinç (Karşılaştırmalı Metin Yayını), Ankara: Türk Dil Kurumu Yayınları. (AKDTYK. TDK. 1268. Eski Uygurca Kütüphanesi 8.)

Tokyürek, Hacer (2019), Eski Uygur Türkçesinde Budizm ve Manihaizm Terimleri, Ankara: Türk Dil Kurumu Yayınları. (AKDTYK. TDK. 1294)

Wilkens, Jens (2007), Das Buch von der Sündentilgung. Edition des alttürkisch-buddhistischen Kšanti Kılguluk Nom Bitig. Teil 1. [Vorwort, Einleitung, Edition]. Teil 2. [Glossar, Transliterationen, Tafeln], Turnhout: Brepols. (BBAW. Akademienvorhaben Turfanforschung. BT. 25, 1 ve 2.) 


\section{Elektronik Kaynaklar}

DDB = Digital Dictionary of Buddhism, www.buddhism-dict.net (Erişim tarihi: 27.03.2020).

U 1305 ([T I] 9): [ön:] http://turfan.bbaw.de/dta/u/images/u1305seite1.jpg (Erişim tarihi 25.03.2020) ve [arka:] http://turfan.bbaw.de/dta/u/images/u1305seite2.jpg (Erişim tarihi: 25.03.2020)

U 1307 ([T I] 8): [ön:] http://turfan.bbaw.de/dta/u/images/u1307seite2.jpg (Erişim tarihi 25.03.2020) ve [arka:] http://turfan.bbaw.de/dta/u/images/u1307seite1.jpg (Erişim tarihi: 25.03 .2020 )

U 1309 ([T I] 7): [ön:] http://turfan.bbaw.de/dta/u/images/u1309seite1.jpg (Erişim tarihi: 25.03.2020) ve [arka:] http://turfan.bbaw.de/dta/u/images/u1309seite2.jpg (Erişim tarihi 25.03.2020)

U 1320 ([T I L] 3): [ön:] http://turfan.bbaw.de/dta/u/images/u1320seite2.jpg (Erişim tarihi 25.03.2020) ve [arka:] http://turfan.bbaw.de/dta/u/images/u1320seite1.jpg (Erişim tarihi: 25.03.2020) 